\title{
LA PROBLEMÁTICA DEL DESEO Y SU LIBERACIÓN EN EL PENSAMIENTO DE KRISHNAMURTI
}

\section{THE PROBLEM OF DESIRE AND ITS RELEASE IN THE THOUGHT OF KRISHNAMURTI}

\author{
MANuel SuANCes Marcos* \\ UNED
}

RESUMEN: Krishnamurti aborda la problemática complejidad del deseo mostrando simultáneamente su fuerza y contradicción. Sin juzgarlo, explica cómo el deseo es el motor de la vida que no puede reprimirse. Vivir sin deseos es carecer de vida, sensibilidad y belleza. Cuando el deseo es comprendido así, entonces se convierte en una gran pasión para vivir y en fuente de energía. Todos estos aspectos son analizados en este artículo.

Palabras ClAVE: Krishnamurti, deseo, impulso, placer, represión, sublimación.

ABSTRACT: Without making a judgment, Krishnamurti shows how desire is the engine of life that can not be repressed. Living without desires is to have no life, to lack sensitivity and beauty. When desire is understood in this way, it then becomes a passion to live and a source of energy. Moreover, desire that is understood and turned into passion leads to the love that is the fullness of life. A specific section on sexual desire ends this reflection.

KEYWORDS: Krishnamurti, desire, impulse, pleasure, repression, sublimation.

\section{Introducción}

La extraordinaria figura y mensaje de Jiddu Krishnamurti sigue impregnando e influyendo en todos los ámbitos de la cultura y el pensamiento actual. La

\footnotetext{
*E-mail: asuances@fsof.uned.es
} 
sabiduría de este gigante del siglo XX va calando paulatinamente en los estratos más diversos de la sociedad y de las culturas. Es un patrimonio espiritual que pertenece a la humanidad entera.

Su posición resulta sorprendente. Se sitúa críticamente frente a todo tipo de cultura, religión y filosofía, pero sin caer en relativismos disolventes ni en el pensamiento light. Al contrario, su mensaje tiene tal fuerza, contenido y coherencia que actúa como polo de atracción para los seres humanos que buscan la verdad y la liberación. Critica a Oriente y Occidente; y, conociendo ambos, muestra un camino que trasciende el dualismo de ambos.

El núcleo de su mensaje - tal y como expuso en aquel solemne acto en que disolvió la Orden de la Estrella - es que todos los hombres sean absoluta e incondicionalmente libres. Una gran parte de su doctrina que impregna su pensamiento es esa libertad que dará acceso al reino de la plenitud vital y espiritual.

Krishnamurti sondea el complejo ámbito psicológico o sea, el fondo del alma humana donde instintos e impulsos vitales forman la trama sobre la que pivota nuestra libertad. Uno de esos impulsos es el deseo. Este es una imponente fuerza de cuya orientación depende en gran parte nuestro destino. Es preciso pues encararlo con toda lucidez y este es el reto que aborda ahora Krishnamurti con el discernimiento característico de su sabiduría.

\section{Problemática del deseo}

Lo primero que se presenta a la atención en este tema es la fuerza y la contradicción con que aparece el deseo. $\mathrm{Y}$, por mucho que vigilemos, se introduce por cualquiera de los poros de la conciencia:

Conocemos ¿no es cierto?, el deseo que es contradictorio, que es torturante, que empuja en distintas direcciones; el dolor, la confusión, la ansiedad del deseo, y el disciplinarlo, el someterlo a control. Y en la eterna batalla con él, lo torcemos, dejándolo desfigurado e irreconocible; pero él está ahí, constantemente vigilando, aguardando, empujando. Hagáis lo que hiciereis: sublimarlo, huir de él, rechazarlo o aceptarlo, darle rienda suelta, siempre está ahí (El estado creativo de la mente, p. 257). 
Cualquiera de nosotros podría hacer suya esta descripción que hace un oyente de Krishnamurti que acude al maestro en demanda de ayuda:

El deseo siempre está ahí, unas veces ardiendo furiosamente y otras latente, pero listo para reavivarse; y el problema es lo que uno va a hacer con ello. Cuando el deseo está latente, todo mi ser está bastante en calma, más cuando está despierto, me siento muy perturbado; me vuelvo inquieto, febrilmente activo, hasta que ese particular deseo es satisfecho. Me calmo entonces relativamente... sólo para ver que el deseo empieza de nuevo otra vez, acaso con un objeto diferente. Es como el agua a presión: por muy alta que construyáis la presa, se filtra por las hendiduras, contornea la extremidad o rebosa el borde superior. He llegado casi a torturarme tratando de trascender el deseo, pero al cabo de mis mejores esfuerzos, el deseo sigue ahí, sonriente o ceñudo (Comentarios sobre el vivir, 2a parte, pp. 179-80).

Todos, pues, vivimos torturados bajo el yugo del deseo: sea éste el deseo de poder, de posición, de fama, de sexo, de riqueza... El problema está en que no aparece un solo deseo sino muchos y en contradicción entre sí. Porque presionan en diferentes direcciones. Cada uno busca su satisfacción tratándose de imponer a los demás. De este modo causan una interminable carrera de luchas y tensiones dolorosas.

La mente es así un completo campo de batalla entre sus propios deseos; y lo peor es que, al parecer, cualquier esfuerzo para encauzarlos o erradicarlos resulta inútil. Es más, el esfuerzo acentúa el conflicto. Y es que el esfuerzo de la mente por liberarse del deseo es también deseo. En consecuencia, la mente se halla atrapada en su propio círculo vicioso.

Por si fuera poco el caos y el sufrimiento que organiza en nosotros el deseo, viene la sociedad con sus potentes medios a inflamarlo y estimularlo. Cuanto más comercial es el uso de las cosas, tanto más crece el deseo. Podemos constatarlo a través del mercantilismo y la avidez del consumo. Por medio de la propaganda el deseo es mantenido, alimentado e inflamado. Y esto ocurre en todo el mundo; Krishnamurti lo constata también en :

Uno ve que esto sucede actualmente en todo el mundo. En la India, por ejemplo, está comenzando a extenderse este deseo con su satisfacción ins- 
tantánea. Y no es que yo conozca a la India mucho mejor que Norteamérica porque, aunque voy todos los años, no he vivido allá por mucho tiempo. Antes, en la sociedad brahmánica, había cierta restricción, cierta disciplina tradicional que decía: "No te intereses en el mundo y en las cosas, no son importantes. Lo importante es el descubrimiento de la verdad, de Brahman, de la realidad, etcétera». Pero ahora todo eso ha desaparecido, ahora les inflaman el deseo: "Compra más, no te satisfagas con dos pares de pantalones, posee una docena». Este sentimiento de excitación en las posesiones es estimulado por medio del comercio, del consumo y de la propaganda (Una manera completamente distinta de vivir, pp. 124-125).

Pero resulta que esta estimulación del deseo va en aumento. Y ello por una poderosa razón que Krishnamurti analiza despacio. Porque, una vez satisfecho un deseo, el placer se debilita y se requiere un estímulo más intenso la próxima vez:

Es lo que están haciendo los diseñadores: cada año hay una moda nueva. Existe esta estimulación del deseo. Es realmente muy alarmante en cierto sentido la manera como la gente está utilizando, estimulando el deseo de adquirir dinero, posesiones; todo el ciclo de una vida absolutamente sofisticado, una vida en la que hay satisfacción instantánea del deseo y el sentimiento de que si uno no lo satisface, si no actúa así, hay frustración (Ibidem, p. 125).

La estimulación del deseo se basa pues en la frustración. Ésta crea un vacío que intenta llenarse por nuevos y más estimulantes placeres. Krishnamurti se detiene aquí y da en la diana del problema. ¿Por qué tanto deseo? ¿Qué queremos de verdad? ¿Qué es lo que verdaderamente deseamos en el fondo de nuestro ser? ¿Qué es eso que nos coge, que nos cautiva por completo? El placer. Nuestra mente se ajusta al placer y desea más y más placer. En realidad es lo único que deseamos:

Nuestras mentes se ajustan por completo al patrón del placer, y la vida no es mero placer, obviamente. Pero nosotros deseamos placer. Eso es lo único que de veras buscamos honda y secretamente en lo interno. Procuramos obtener placer de todas las cosas, y el placer, si uno lo observa, no sólo aísla y confunde a la mente, sino que también crea valores que no son genuinos ni reales. Por lo tanto, el placer engendra ilusión. Una mente que busca pla- 
cer, como casi todos lo hacemos, no sólo se aísla sino que invariablemente, tiene que hallarse en un estado de contradicción en todas sus relaciones, ya sea en su relación con las ideas, con las personas o con la propiedad; por fuerza tiene que vivir siempre en conflicto. Ésa es, entonces, una de las cosas que hemos de comprender: que nuestra búsqueda en la vida es, fundamentalmente, la exigencia, el impulso, el anhelo de placer (Amor, sexo y castidad, pp. 35-36).

Pero a esa búsqueda de placer que inexorablemente intenta el deseo va intrínsecamente unida la frustración. Dolor y placer son dos manifestaciones de la misma realidad que es el deseo. Nos damos cuenta de nuestro deseo cuando existe la perturbación del placer o del dolor. Cuando somos conscientes del conflicto, de la perturbación, es cuando hay conocimiento del deseo. Así pues, el conflicto y el deseo no son dos estados diferentes. Es en el conflicto donde se manifiesta y sentimos el deseo:

¿Son el conflicto y el deseo dos estados diferentes? Si lo son, nuestro interrogante debe llevar a la ilusión. Si no existiera la perturbación del placer o del dolor, del necesitar, del buscar, del realizar, ya sea negativa o positivamente, ¿habría deseo? ¿Y queremos nosotros desembarazarnos de la perturbación? Si podemos comprender esto, entonces estaremos en condiciones de captar el significado del deseo. El conflicto es autoconciencia; el enfoque de la atención en la perturbación es el deseo. ¿Es que Ud. quiere librarse del elemento que causa conflicto en el deseo, y retener el elemento placentero? Tanto el placer como el conflicto son perturbadores, ¿no es cierto? ¿O cree Ud. que el placer no perturba? (Comentarios sobre el vivir, $1^{\text {a }}$ parte, p. 159).

El placer conlleva perturbación. El ansia de placer va siempre en aumento pidiendo más y más. Y esta ansia es tan dolorosa como el impulso de evitar el dolor. Krishnamurti está siempre al quite en este punto. Tan perturbador es buscar el placer como huir del dolor. Queremos mantener el deseo placentero y evitar el penoso. Pero bien mirados, ambos son igualmente perturbadores.

Este es el conflicto de la dualidad inherente a la propia estructura del deseo. Y no hay nada de enigmático en ello. El deseo busca siempre la realización, pero no la consigue, porque éste no tiene fin y por tanto la frustración planea al mismo tiempo que la aparición del deseo. Ambas cosas son inseparables. Al estar 
insatisfechos con un determinado objeto del deseo, le hallamos un sustituto. Nos movemos sin cesar de un deseo a otro que consideramos superior, más noble o refinado. Pero por refinado o sublime que sea, sigue siendo deseo. $Y$ en este incesante movimiento se produce la lucha interminable que es el conflicto de los opuestos:

Donde hay deseo, hay conflicto y contradicción; y ya sea que nos demos o no cuenta de ello, la contradicción invariablemente trae dolor. El deseo, pues, es dolor, tenga él por objeto cosas triviales o grandes cosas. El deseo trae inevitablemente consigo su propio opuesto; y por ello es importante — ¿no es así? - comprender todo el proceso del pensamiento, que es el «yo» y lo «mío» (Sólo la verdad trae la libertad, p. 116).

No hay modo de salir o de romper esa dinámica de frustración a la que aboca el deseo. Así responde Krishnamurti a un visitante que va a pedirle orientación sobre este problema:

¿No es posible nunca obtener realización, sin el dolor de la frustración?

¿No lo sabéis? ¿No habéis experimentado el breve placer de la realización, y no es seguida invariablemente por la ansiedad, la pena?

He observado eso, pero de una u otra manera trata uno de ponerse a cubierto del dolor.

¿Y lo habéis conseguido?

Todavía no, pero siempre se espera lograrlo.

Vuestro principal interés durante toda la vida es cómo preveniros contra ese sufrimiento; y así empezáis a disciplinar el deseo; decís: «Este es el deseo bueno, el otro es malo, inmoral». Cultiváis el deseo ideal, lo que debería ser, mientras estáis preso de lo que no debería ser...

¿Os han ayudado vuestros ideales a libraros del sufrimiento, o es que os han ayudado meramente a seguir adelante con el placer, mientras os decís idealmente que no deberíais hacerlo? Así, el dolor y el placer del deseo continúan. De hecho no queréis liberaros de uno ni de otro. Queréis ir a la deriva con el dolor y el placer del deseo, hablando mientras tanto de ideales y todo eso (Comentarios sobre el vivir, $3^{\mathrm{a}}$ parte, p. 181). 
En definitiva, el problema del deseo es que origina contradicción en cada uno de nosotros porque no puede en ningún momento producir integración y es sólo en ese estado de integración o integridad donde existe la posibilidad de ir más allá de las contradicciones creadas en la mente por el mismo deseo.

\section{Naturaleza y formas del deseo}

Encajado el primer impacto del deseo que es su vehemencia y contradicción, Krishnamurti se dispone ahora a sondear su ser. Lo hace con el amor y dedicación que requiere una realidad tan trascendental para el hombre. Y aborda su naturaleza no dando definiciones formales o estereotipadas que son tan estériles como inútiles; sino acercándose a él desde diversas perspectivas, destacando poco a poco matices, perfiles y rasgos. ¿Qué es el deseo? Se trata de éste y no de sus diversos objetos. Se trata del hecho mismo del deseo y del lugar que le corresponde, no de la idea del deseo. No importan las opiniones o juicios acerca de él, sino el hecho de que los seres humanos tienen deseos colosales, contradictorios, aburridos, ilusorios. El deseo se presenta como un instinto muy activo y exigente, como una actividad absorbente que se desarrolla en nosotros constantemente. Es como el hambre que trata de llenar su apetito. Deseo y apetito son lo mismo. «El deseo es el más apremiante y vital impulso de nuestra vida. Nos referimos al deseo mismo, no al deseo por una cosa particular». Y ¿qué es este impulso? Energía que no se puede reprimir:

El deseo es energía, y eso tiene que comprenderse; no es posible limitarse a reprimir el deseo o hacer que se ajuste. Cualquier esfuerzo para coartar o disciplinar el deseo contribuye a la existencia del conflicto, el cual trae consigo insensibilidad. Todos los recursos intrincados del deseo deben ser conocidos y entendidos. No se nos puede enseñar ni podemos aprender los recursos del deseo" (Amor, sexo y compasión, p. 41).

Y ¿qué busca el deseo poniendo en el empeño su formidable energía? Busca siempre placer y satisfacción, sean deseos positivos o negativos, de esta o de aquella clase. Y esto se convierte en un hábito mecánico que sólo las crisis y rupturas internas ponen de manifiesto. Las grandes emociones internas rompen esa dinámica de búsqueda incesante de satisfacción: 
Estamos familiarizados con el deseo positivo y el deseo negativo, el ser y el no ser, el realizarnos y el no realizarnos. Ahora bien, el deseo no es emoción; el deseo es el resultado de una mente que siempre está buscando satisfacción y cuyos valores se basan en la satisfacción. Estar satisfecho es el motivo que hay detrás de todo deseo. La mente busca siempre la satisfacción a cualquier costo, y si ésta se ve bloqueada en una dirección, busca lograr su propósito en otra. Todo esfuerzo, todo poder direccional de la mente es para que ésta pueda satisfacerse. Por eso la satisfacción se vuelve un hábito mental mecánico. En momentos de gran emoción, de amor profundo, la mente no depende del deseo ni busca satisfacción (Obras completas, tomo III, El espejo de la relación, p. 189).

Esta búsqueda de satisfacción es algo estructural al deseo. Y, por consiguiente, se manifiesta en cualquiera de sus objetos, sean estos superficiales o profundos:

Los deseos son tanto abiertos como ocultos, conscientes y disimulados. Los encubiertos son de importancia mucho más grande que los evidentes; pero no podemos familiarizarnos con los más profundos si no han sido comprendidos y domesticados los superficiales. No es que los deseos conscientes hayan de ser suprimidos, sublimados o amoldados a cualquier norma, pero tienen que ser observados y calmarse. Al calmarse la agitación superficial, hay una posibilidad de que los deseos más profundos, los motivos y las intenciones, salgan a la superficie (Comentarios sobre el vivir, $2^{\text {a }}$ parte, p. 86).

Esta variabilidad del deseo, en cuanto a sus objetos, se pone también de manifiesto desde otra perspectiva que atiende no tanto a la naturaleza de éstos, como a su rasgo estructural de hallar satisfacción en su continua renovación:

Cuando me doy cuenta de toda esta estructura del deseo, veo cómo mi mente se ha convertido en un centro muerto, en un proceso mecánico de la memoria. Al cansarme de un deseo, automáticamente quiero encontrar satisfacción en otro. Mi mente experimenta siempre en términos de sensación, es el instrumento de la sensación. Al aburrirme con una determinada sensación, busco una sensación nueva que podrá ser lo que llamo «realización de Dios»; pero esto sigue siendo una sensación. Estoy harto de este mundo y sus afanes, y deseo la paz, una paz que sea eterna; así es que medito, domino mi mente y la disciplino a fin de experimentar esta paz. La experiencia 
de esta paz sigue siendo una sensación. Mi mente, pues, es el instrumento mecánico de la sensación, de la memoria, un centro muerto desde el cual yo actúo y pienso (La libertad primera y última, pp. 103-104).

Los objetos que persigue el deseo son proyecciones de la mente en forma de símbolos, imágenes, recuerdos. De éstos obtenemos placer, satisfacción. Las palabras «Dios», «amor», «solidaridad», «democracia», «nacionalismo», etc. despiertan sensaciones satisfactorias que la mente elabora constantemente aferrándose a ellas. Pero éstas acaban y vamos de una a otra sin parar. Así se fortalece el hábito mental de buscar sensaciones placenteras. Y la mente queda atrapada en este proceso mecánico del que desea salir:

Por poco que hayamos examinado esto ya estamos familiarizados con este proceso y parece que seamos incapaces de avanzar más allá. Queremos avanzar porque estamos cansados de esta interminable rutina, de esta búsqueda mecánica de sensaciones. La mente, pues, proyecta la idea de la verdad o de Dios; sueña con un cambio trascendental y con desempeñar un papel principal en ese cambio, y etcétera, etcétera. De ahí que no haya nunca un estado creador. Veo desarrollarse en mí mismo este proceso del deseo que es mecánico, que se repite, que mantiene a la mente en un proceso de rutina y hace de ella un centro del pasado muerto en el que no hay espontaneidad creadora (Ibidem, pp. 104-105).

Pero, una vez puesta de manifiesto esta variabilidad y multiplicidad de los objetos, Krishnamurti postula la unidad del deseo. Aquellos son innumerables, éste es uno. Hay objetos más permanentes, otros más pasajeros, los hay de sexo y poder, pueriles o poderosos. Cambian de forma y contenido. Pero el deseo persiste y se mantiene en sí mismo. Ahora bien el deseo, como tal, no aparece solo, sino siempre en los objetos:

Están, pues, el deseo y el apetito; esto lo hemos examinado un poco, pero ¿que es el deseo? Veo algo e inmediatamente tengo que poseerlo: una bata, un abrigo, una corbata... surge el sentimiento de posesión, el impulso de adquirir, de experimentar, el impulso de realizar un acto que me dará una satisfacción tremenda. La satisfacción podría consistir en la adquisición de algo, de una corbata, de un abrigo, o en dormir con una mujer. Ahora bien, detrás de todo esto está el deseo. Puede que yo desee una casa, que otro desee 
un automóvil y algún otro desee tener conocimiento intelectual. Otro tal vez desee a Dios o la iluminación. Es todo lo mismo. Los objetos varían pero el deseo es el mismo. A un deseo lo llamo noble, al otro innoble, mundano, estúpido. Pero detrás de todas estas cosas está el deseo (Una manera completamente distinta de vivir, pp. 128-129).

Sin captar la unidad del deseo, cualquier cosa que se haga será de escasa importancia. Porque un deseo lleva a otro sin descanso y esa dinámica engendra el conflicto de opuestos. Quedamos así instalados en la contradicción interna y la división. Pero esos deseos que tiran en distintas direcciones provienen de un núcleo, de una unidad a la que es necesario orientar la percepción de la mente para la debida orientación del problema.

Una vez descrita la estructura, Krishnamurti señala un criterio clasificatorio para detectar su naturaleza y es la distinción entre la necesidad y el deseo. Este punto es decisivo:

Deberíamos ser capaces, creo, de discernir la diferencia entre necesidad y deseo. El deseo jamás puede estar integrado, porque el deseo crea siempre contradicción — su propio opuesto-. Mientras que, si pudiéramos comprender la necesidad, veríamos que en ella no hay contradicción alguna. Y es importante, sin duda, darse cuenta de este problema del deseo, que genera contradicciones en cada uno de nosotros, porque el deseo jamás puede, en ningún momento, producir integración; y sólo en el estado de integración, en el estado de totalidad, es posible ir más allá de las contradicciones creadas en la mente por el deseo. Al fin y al cabo, el deseo es sensación, y la sensación es la base del pensamiento, de la mente. Sobre la sensación se asienta todo nuestro pensar, y en tanto no comprendamos el proceso del deseo, estamos obligados a crear en nuestra vida el conflicto de la contradicción (Obras completas, tomo VI, El origen del conflicto, p. 296).

Clarificando el terreno y señalando deseos y necesidades, Krishnamurti traza una línea nítida entre ambos. Las necesidades esenciales son la ropa, el albergue y el alimento. Sin ellos nada podemos hacer. Lo demás son necesidades psicológicas, es decir, deseos no necesarios que la mente ha de vigilar y orientar porque son escapes: 
Necesitamos, por supuesto, ciertas cosas exteriores superficiales, como ropas, albergue y alimento. Ellas son absolutamente indispensables para todos. Pero me pregunto si en verdad necesitamos alguna otra cosa. ¿Hay en realidad alguna necesidad, psicológicamente, del sexo, de la fama, del apremio compulsivo de la ambición, de la perpetua exigencia interior de más y cada vez más? ¿Qué necesitamos, psicológicamente? Creemos necesitar muchísimas cosas, y de eso proviene toda la tristeza de la dependencia. Mas si en realidad penetramos en ello hondamente e inquirimos, ¿hay acaso alguna necesidad esencial psicológica o íntima? Creo que valdría la pena que nos hiciéramos seriamente esta pregunta. La dependencia psicológica en las relaciones, la necesidad de estar en comunión con otro, la necesidad de entregarse a alguna forma de pensamiento y actividad, la necesidad de realizarse, de llegar a ser famoso: todos conocemos tales necesidades y estamos perpetuamente cediendo a ellas. Y creo que sería importante que pudiéramos, cada uno de nosotros, tratar de descubrir lo que son efectivamente nuestras necesidades y hasta qué punto dependemos de ellas (El estado creativo de la mente, p. 255).

Pues bien, tomando la última idea de este texto, Krishnamurti sondea el por qué de esas necesidades psicológicas que tanto apremian y gastan nuestras energías. El diagnóstico no puede ser más profundo y clarividente:

Las necesidades psicológicas son un mecanismo de defensa contra algo que es mucho más significativo y real. La necesidad de realizarse, de ser importante, brota del miedo a algo que está ahí pero que no se conoce, que no ha sido experimentado. La realización y la autoimportancia en el nombre del propio país o de un partido, o en virtud de alguna creencia gratificadora, son escapes del hecho de la propia nada, de la vacuidad y soledad de nuestras actividades autoaislantes. Las necesidades internas, que parecen no tener fin, se multiplican, cambian y continúan. Este es el origen, la fuente del contradictorio y abrasador deseo (Diario I, p. 108).

Este texto pone en jaque nuestro sistema de defensas y describe la causa última de tanto deseo insatisfecho: nuestra pobreza psicológica, el vacío que nada llena. Por esto la comprensión del deseo es esencial y esa comprensión no surge yendo constantemente de un deseo a otro, lo cual es mecánico, contradictorio y destructivo. En cambio, en las necesidades, no hay contradicción. Se satisfacen 
y ello es imprescindible para la vida. El deseo nos subyuga, nos ata y hacemos de él una necesidad, cuando no es tal:

Pero, si somos capaces de comprender la necesidad, veremos que el deseo nos ata, que no origina libertad; y discernir lo que es de veras necesario resulta una tarea difícil, porque el deseo interfiere constantemente con nuestras necesidades. Cuando comprendemos la necesidad, no hay contradicción, pero a fin de comprender la necesidad tenemos que comprender el deseo. Y nuestro problema consiste en que hay una batalla constante desarrollándose entre la necesidad y el deseo, ¿no es así? Toda nuestra estructura social se basa en esta contradicción del deseo. Creemos que estamos progresando cuando nos movemos desde un deseo hacia lo que llamamos «un deseo más elevado»; pero el deseo, alto o bajo, es siempre una contradicción, una fuente de conflicto y de gran sufrimiento (Obras completas, tomo VI, El origen del conflicto, p. 296).

Es preciso ver cómo el deseo opera en nuestra vida cotidiana y cómo confundimos deseos y necesidades. En la necesidad no hay opción o ejercicio de la libertad. Cuando se presenta se satisface de manera inmediata y en ello no hay contradicción, no hay batalla interna ni externa. Tenemos hambre o sed y lo satisfacemos. No hay problema alguno. Éste se plantea cuando se hace de los deseos necesidades y se introduce por tanto la opción. Ésta se basa siempre en nuestro condicionamiento y este es el resultado de nuestros deseos contradictorios. ¿Qué camino elijo si mi deseo convertido en necesidad es el de realizarme? ¿Cómo me realizo? ¿Ganando fama, dinero o ejerciendo el poder? Por tanto si escogemos lo que creemos que es necesario, estamos obligados a generar conflicto, desorden. En cambio cuando juzgamos que algo es verdaderamente necesario, el asunto es muy simple, lo comprendemos inmediatamente y su satisfacción no plantea ningún problema.

Krishnamurti se centra ahora en estas necesidades psicológicas. ¿Por qué se han vuelto tan importantes, por qué tienen esa fuerza tan compulsiva y apremiante? Y aquí no se trata de explicarlas con meras elucubraciones racionales. Es preciso llegar al fondo de su complejidad. ¿Son en sí mismas algo imprescindible o son el disfraz de una carencia más profunda? ¿Por qué tenemos esa invencible necesidad de realizarnos, de «llegar a ser» esto o aquello? ¿Por qué esa ambición ilimitada que no se contenta con nada, ni con viajar, ni con ascensos laborales, 
ni con dinero, ni riqueza? ¿Por qué el sexo se impone con esa fuerza desmesurada? Krishnamurti vuelve a apuntar muy claro:

Ahora bien, cuando lo examináis, dejando de lado la reacción superficial de decir: "¿qué me pasaría si no tuviera éxito en la vida?», creo que hallaréis que hay en ello una cuestión mucho más honda, que es el temor de «no ser», del aislamiento completo, del vacío y de la soledad. Está ahí, profundamente oculta, esta tremenda sensación de ansiedad, este miedo de quedar apartado de todo. Es por eso que nos aferramos a toda clase de relaciones. Es por eso que hay esta necesidad de pertenecer a algo, a un culto, a una sociedad; de entregarse a ciertas actividades, de aferrarse a alguna creencia; porque de ese modo escapamos de esa realidad que está efectivamente ahí, hondamente adentro. Es ese temor, por cierto, el que fuerza la mente, el cerebro, todo el ser, a entregarse a alguna forma de creencia o relación, que luego llega a ser la necesidad, lo necesario (El estado creativo de la mente, pp. 256-257).

Krishnamurti resiste y trata por largo y tendido este tema en que queda involucrada nuestra entera vida psicológica. El abanico de estas artificiales necesidades psicológicas llega hasta los rincones más alejados del alma; tomando el deseo de poder lo analiza y extiende con peculiar agudeza:

Es muy singular cómo cada uno anhela el poder, el poder del dinero, de la posición, la capacidad, el conocimiento. En el ganar poder hay conflicto, confusión y dolor. El ermitaño y el político, la dueña de casa y el científico buscan el poder. Para obtenerlo se matarán y destruirán los unos a los otros. Los ascetas, por medio de la abnegación del yo, del control, de la represión, conquistan ese poder; el político logra ese poder gracias a su palabra, a su capacidad, a su destreza; la esposa y el marido sienten este poder mediante el dominio del uno sobre el otro; el sacerdote que ha asumido, que ha tomado a su cargo la responsabilidad de su dios, conoce este poder. Todos buscan este poder, desean estar asociados con el poder divino o mundano (Diario I, p. 132).

Cuando uno está lúcidamente atento a ese afán de poder y termina con él, se encuentra consigo mismo tal como es, con su soledad y su nada:

Con la completa terminación de este poder con su confusión, conflicto 
y dolor, cada uno se enfrenta a lo que es, un manojo de recuerdos y una soledad que se ahonda más y más. El deseo de poder y de éxito es un escape de esta triste soledad y de las cenizas que son los recuerdos (Diario I, p. 133).

Ante este deseo de poder que se manifiesta en el deseo de ser alguien, de alardear, no queda otra cosa que prescindir de esa falsa apariencia y quedarnos con lo que somos:

Es extraño el deseo de alardear ante los demás, de ser alguien. La envidia es odio y la vanidad corrompe. Parece tan difícil e imposible ser sencillo, ser lo que somos y no presumir. Ser lo que uno es resulta en sí mismo muy arduo, ser lo que se es constituye una cuestión muy compleja; porque uno está siempre cambiando, nunca es el mismo y cada instante revela una nueva faceta, una nueva profundidad, una superficie nueva. No es posible ser en un instante todo esto, porque cada instante conlleva su propio cambio. De modo que si uno es siquiera un poco inteligente, renuncia a ser esto o aquello (Diario I, p. 218).

De modo que ser lo que uno realmente es, resulta un asunto difícil. Es preciso estar despierto para no diluirse en esos deseos de aparentar, de llegar a ser. Tiene uno que afrontar esas cosas y reducirlas a nada mediante la comprensión. La negación de esto es algo positivo. Ser como la nada no es un estado negativo. La negación de lo que falsamente uno ha sido, es la más positiva de las acciones. Es la libertad que proporciona esa energía positiva del vivir auténtico.

Para terminar de perfilar la naturaleza de nuestras necesidades psicológicas, Krishnamurti añade un último rasgo. La fuerza motora que está detrás del deseo es el yo superior, la virtud, o como quiera llamarse. Pero esas cosas en el fondo son el deseo mismo recubierto bajo tan tranquilizantes palabras. En definitiva, el yo es el haz de los deseos y él mismo es deseo:

El experimentador no está separado de aquello con lo cual está experimentando. La verdad de esto tiene que verse. Vos, que estáis experimentando con vuestros deseos, no sois una entidad aparte de esos deseos, ¿̨verdad? El «yo» que dice: «suprimiré este deseo e iré en pos de aquel», es él mismo resultado de todo deseo, ¿¿no es así? (Comentarios sobre el vivir, 2a parte, p. 86). 
Si en cada deseo concreto somos conscientes de que ese deseo es el yo, entonces no se da la ilusión del experimentador como entidad separada, sin relación al deseo mismo. Mientras el yo se esfuerza en verse libre del deseo, generará más conflicto porque él es el deseo; entonces lo que hará será reforzar éste en otra dirección y rechazar la que experimentaba hasta ese momento. Y así el yo va de un deseo a otro en búsqueda de realización, pero en el fondo huyendo de sí mismo:

La esencia del yo es este deseo y el cambio constante de los deseos, y la eterna búsqueda, de una atadura a otra, de un templo a otro templo, de un compromiso a otro. El comprometerse uno a sí mismo con una idea, con una fórmula, el pertenecer a algo, a alguna secta, a algún dogma, todo ello está impulsado por el deseo, es la esencia del yo que toma la forma de las más altruistas actividades. Es un pretexto, una máscara. La libertad con respecto a los deseos, es madurez. Con esta libertad adviene la intensidad que no tiene causa ni es utilitaria (Diario I, pp. 84-85).

\section{Proceso del deseo}

Una vez que ha circunscrito la naturaleza del deseo, Krishnamurti se propone ahora descifrar su complejo proceso. El deseo es algo vivo que nace y se impregna en otras manifestaciones vitales. Y así le sigue de cerca viendo cómo se prepara, qué circunstancias facilitan su aparición, cómo se desenvuelve, qué lleva consigo y dónde termina. El proceso es complejo desde el punto de vista de la vivencia, pero sencillo en su descripción. Krishnamurti alude a él en mil pasajes, pero el esquema es siempre el mismo en su sencillez: percepción, sensación, contacto, pensamiento e imagen y deseo. Veamos despacio cada uno de esos pasos y sus respectivas implicaciones.

En primer lugar, percepción: vemos un paisaje lleno de encanto, una espléndida puesta de sol, una mujer bella, el rostro vivo de una persona equilibrada, un magnífico chalet rodeado de jardín y así infinidad de cosas. He aquí la actitud primera que cabe ante eso:

Contemplo todas estas cosas con intenso deleite y, mientras las observo, no hay ningún observador sino sólo una belleza pura como el amor. Por un momento estoy ausente con todos mis problemas, inquietudes y pesares, no 
hay más que esa cosa maravillosa. Puedo mirarla con alegría y olvidarla al cabo de un instante, o bien interviene la mente y entonces empieza el problema (Limpia tu mente, p. 45).

Bien, ahí está el gozo que nos proporcionan las cosas o personas bellas. Esas maravillas causan en nosotros una sensación. No nos dejan indiferentes. Esa sensación es inseparable del impacto visual que acabamos de tener. Al ver ese hermoso jardín, esa bella escultura, tenemos la sensación de algo maravilloso:

Usted ve un jarrón hermoso, una bella escultura, una estatua preciosa, del Antiguo Egipto o griega, y la mira. Conforme la mira, si le permiten tocarla, la toca. Vea la intensidad de esa figura sentada en una silla o con las piernas cruzadas. De eso resulta una sensación, ¿̨no es cierto? "iQué cosa maravillosa»! Y partiendo de esa sensación, el deseo dice: «Ojalá la tuviera en mi cuarto. Ojalá pudiera contemplarla, tocarla todos los días». Aparece el orgullo de la posesión, de tener una cosa tan maravillosa (Reflexiones sobre el ser, p. 140).

Es aquí donde el deseo va a aparecer enseguida. No contentos con ver y gozar desprendidamente de esas maravillas, aparece el pensamiento queriendo prolongar en el tiempo esa sensación y tratando de poseer esas cosas. Aquí es donde Krishnamurti insiste en la inflexión que se produce en este proceso: hasta que aparece el pensamiento todo es bueno y sano; no hay nada que reprimir. Pero en cuanto aparece aquél, con su afán de posesión, entonces surge el deseo con su vehemencia al servicio del experimentador. Ha habido una ruptura:

Dijimos que el deseo es el movimiento de percepción, ver, contacto, sensación, pensamiento en forma de deseo, con su imagen. Ahora estamos diciendo que ver, tocar, sensación, es normal, sano. Déjelo ahí. No permita que el pensamiento intervenga, asuma el control sobre ella y la convierta en deseo. Comprenda esto y entonces verá que no habrá supresión del deseo.

O sea, usted ve una casa hermosa, bien proporcionada, con ventanas preciosas, un bello jardín, bien cuidado, con un techo que se funde con el cielo, paredes que son gruesas y forman parte de la tierra. La mira, hay sensación. La toca. Puede que no la toque realmente, pero la toca con sus ojos. Huele el aire, las hierbas aromáticas, el césped recién cortado. ¿Y no puede 
dejarlo ahí? ¿Por qué la sensación se convierte en deseo? Cuando hay percepción, contacto, sensación, es natural, es hermoso ver las cosas atractivas, o algo feo. Entonces, para detenerlo ahí, diga: «Es una casa hermosa». Entonces, no hay grabación del pensamiento que dice: «Ójala tuviera esa casa», lo cual es deseo y la continuación del deseo (Ibídem, p. 141).

Es este un punto tan decisivo que Krishnamurti lo da mil vueltas poniendo siempre de relieve que la intervención del pensamiento en el proceso da un nuevo giro a éste:

Uno encuentra deleite en algo, el deleite que surge naturalmente cuando contemplamos algo muy bello. En este instante, en ese segundo no hay placer ni disfrute, sólo existe el sentido de observación. En esa observación está ausente el «yo». Cuando miramos una montaña con su cumbre nevada, con sus valles, su inmensidad y magnificencia, ello aleja todo pensamiento. Allí está esa grandeza frente a nosotros, y hay deleite. Después viene el pensamiento y registra como recuerdo lo maravillosa y encantadora que fue esa experiencia. Entonces, ese registro, ese recuerdo es cultivado, y ese cultivo se convierte en placer. Cada vez que el pensamiento interfiere con el sentido de la belleza, con el sentido de la inmensidad de algo — un fragmento de poesía, una cortina de lluvia, un árbol solitario en medio del campo-, se produce un registro. Pero lo importante es ver eso y no registrarlo. En el momento en que lo registramos, en que registramos la belleza de ello, ese registro mismo pone en acción el pensamiento; después surge el deseo de perseguir esa belleza, deseo que se convierte en la persecución del placer (Amor, sexo y castidad, p. 37).

Para seguir adelante, Krishnamurti condensa una vez más el proceso, en orden a insistir luego en el punto álgido:

Cuando vemos algo, el ver origina una respuesta. Vemos una camisa verde, o un vestido verde, y el acto de ver despierta la respuesta. Entonces se produce el contacto. Luego, a causa del contacto, el pensamiento crea la imagen de uno con esa camisa o ese vestido, y entonces surge el deseo. $\mathrm{O}$ uno ve un automóvil detenido en el camino; tiene hermosas formas, un pulido perfecto, y detrás de ello se percibe muchísimo poder. Entones uno camina alrededor del auto, examina el motor... El pensamiento crea la imagen de 
uno mismo que entra en el automóvil, enciende el motor y, poniendo los pies en los pedales, lo maneja. Así es como comienza el deseo; el origen del deseo es el pensamiento que crea la imagen; hasta llegar a ese punto, no hay deseo. Están las respuestas sensorias, que son normales, pero luego el pensamiento crea la imagen y desde ese instante se pone en marcha el deseo (Ibidem, p. 45).

Pues bien, llegados al punto álgido, Krishnamurti se pregunta: ¿es posible detener al pensamiento para tener así en propias manos las riendas del proceso? Porque es dominando el pensamiento como podremos orientar el deseo. Es el pensamiento el que da una dirección u otra al deseo. ¿Puede no haber interferencia del pensamiento, en el goce inmediato de las cosas bellas? ¿Qué hará la mente para impedir que el pensamiento intervenga?:

De modo que el pensamiento nutre, sostiene e imprime una dirección al placer. No había placer en el instante de la percepción de aquel árbol, de la colina, las sombras, los venados, el agua, la pradera. Toda la cosa era realmente no verbal, no romántica y demás; era percepción. No tenía nada que ver conmigo o con usted, estaba ahí. Entonces viene el pensamiento y da forma al recuerdo de ello, a la continuación de ese recuerdo mañana y a la exigencia y persecución de eso. Y cuando vuelvo a eso el día de mañana ya no es lo mismo. Me siento un poco sacudido. Me digo que estaba inspirado, que debo encontrar un medio de inspirarme nuevamente (Una manera completamente distinta de vivir, p. 143).

Sin ver esta continuidad que da el pensamiento al deseo, no puede comprenderse la fuerza y dirección de éste. Vemos cómo surge el deseo, lo cual es bastante simple. El problema es lo que le da continuidad y, por tanto, le fortalece y convierte en férrea voluntad:

Y bien, ¿qué es lo que da continuidad al deseo? Veo algo hermoso, atractivo; ha surgido un deseo. Y ahora debo averiguar qué le otorga al deseo la vitalidad, la continuidad de su fuerza. Hay algo que es placentero, que yo siento deseable y le doy continuidad pensando en ello. Uno piensa en el sexo. Ustedes piensan en él y le dan continuidad. O piensan en el dolor, en la desdicha que experimentaron ayer, y así también dan continuidad a eso. Por lo tanto, el surgimiento del deseo es natural, inevitable; deben experimentar el 
deseo, deben reaccionar; de lo contrario, son una entidad muerta. Pero lo importante es ver, descubrir por uno mismo cuándo hay que dar continuidad al deseo y cuándo no.

Por lo tanto, tienen que comprender la estructura del pensamiento, el cual influye sobre el deseo, lo controla, lo moldea y le otorga continuidad. ¿Correcto? Eso está claro. El pensamiento funciona conforme a la memoria, etc.; no vamos a examinar eso ahora. Sólo estamos señalando cómo el deseo se fortalece cuando uno piensa constantemente en él y le da una continuidad, la cual se convierte en la voluntad del deseo (Amor, sexo y castidad, p. 51).

Queda entonces suficientemente claro que el pensamiento es la raíz de la continuidad del deseo y, por tanto, de la constante demanda de placer. El pensamiento registra lo bello y agradable y quiere atesorarlo y darle continuidad. Ahí está el placer y también, y por lo mismo, el dolor. Si al ver algo hermoso, uno no tuviera pensamientos, la cosa quedaría en eso. Pero el pensamiento no se para ahí y quiere poseer esas cosas bellas percibidas. De ahí fluye todo el movimiento del pensar. Entonces, para atajar el tema, Krishnamurti se plantea una pregunta bien sencilla. ¿Es posible disfrutar de las cosas buenas y bellas sin registrarlas? ¿Sin que el pensamiento intervenga postulando su continuidad y almacenándolas en la memoria? ¿Es posible dejar de registrar las experiencias agradables y también los desagradables? Así lo expresa Krishnamurti a uno de sus interlocutores en este diálogo:

K. Entonces, ¿es posible disfrutar, deleitarse con esa hermosa escena y no permitir que se introduzca el pensamiento? ¿Es posible? Le mostraré que es posible, completamente posible, si uno está atento a ese instante, completamente atento. ¿¿ntiende, señor?

A. Lo cual no tiene nada que ver con retorcerse en un esfuerzo muscular para lograrlo.

K. Correcto, sólo estar totalmente ahí. Cuando usted ve una puesta de Sol, véala completamente. Cuando ve la hermosa forma de un automóvil, véala. No deje que empiece el pensamiento. Eso significa estar completa y supremamente atento, con su mente, su cuerpo, sus nervios, con sus ojos y oídos, todo ha de hallarse atento. Entonces el pensamiento no interviene en absoluto (Una manera completamente distinta de vivir, p. 145). 
Es este un punto importante en el pensamiento de Krishnamurti. Es preciso vivir de instante en instante, en este orden de cosas; no en otro, por cierto. Se trata de agotar — reducir a cenizas, dice él— cualquier experiencia psicológica: entregarse a ella en el presente con todo el alma y a continuación despedirse de ella. La memoria, que es el depósito que recoge experiencias y pensamientos juega una mala pasada en este sentido. El registro de experiencias prolonga el fortalecimiento del deseo que requiere repetir las vivencias de placer y evitar las de dolor. "Hay disfrute, un sentido maravilloso de disfrutar cada instante y terminar con ello a medida que uno lo va viviendo. Uno no conserva el disfrute que pasó; eso se convierte en placer y no tiene sentido. La repetición del placer es monotonía y aburrimiento" (Ibídem, pp. 152-153). Los recuerdos acumulados $\mathrm{y}$ asociados estimulan el deseo. O sea, la memoria es parte del deseo:

El deseo es estimulado por la asociación y el recuerdo, la memoria es parte del deseo. El recuerdo de lo agradable y lo desagradable nutre el deseo y lo divide en deseos opuestos y en conflicto. La mente se identifica con lo agradable, como opuesto a lo desagradable; mediante la selección del dolor y el placer la mente separa el deseo, dividiéndolo en diferentes categorías de empeños y valores (Comentarios sobre el vivir, 2a parte, p. 85).

Con ese pasado acumulado la mente se enfrenta a nuevos deseos y situaciones y, con ello, fracasa. El pasado es una rémora ante el desafío que plantea la vida con su continua novedad. Nuestro deseo es que el placer que hemos experimentado se repita. Pero éste nubla la mente y la hace dar vueltas, creando valores falsos e irreales.

\section{Actitudes ante el deseo: la represión}

Visto el proceso del deseo y sabiendo que éste puede llevarnos al desastre, se plantea el problema de intervenir en ese proceso para que no llegue a su fin. Las religiones, la moral, la filosofía, la sociedad, han exigido al hombre que reforme sus deseos. Esta exigencia tiene un momento álgido. ¿Cuándo intervenimos en el proceso, al principio, cuando nuestra sensibilidad está a flor de piel? ¿Conviene entonces erradicarlo de raíz? ¿№ es eso una especie de castración inútil? ¿Cuándo intervenir entonces, después de haber sentido el gozo de lo bello? Ha habido posturas para todos los gustos. Y la historia ha sido muy prolija en este sentido. 
Pero ha abundado más la postura de la represión que la del cultivo equilibrado del deseo. Las posturas ante éste han oscilado entre la permisividad más absoluta, la disciplina, la represión y la sublimación. En este sentido, Krishnamurti, consciente de los desastres que han causado tanto la permisividad como la represión, se sitúa en una actitud verdaderamente equilibrada. Es este un punto en que muestra su sensibilidad y sobre todo, la sintonía del cuerpo y alma. Aquí brilla su auténtica maestría. Ha percibido demasiado claro los desastres y el dolor acarreados por tantas creencias e ideologías. Éstas han hecho estragos.

Viendo la compleja realidad del deseo, ¿qué hay que hacer con él, dominarlo o darle rienda suelta?:

$\mathrm{Y}$ ¿puede dominarse el deseo? ¿Debe someterse a control? ¿ $\mathrm{O}$ tiene uno que darle plena salida, plena expresión? Ese es el problema. Si le da uno plena expresión, siempre hay la incertidumbre de cuál puede ser el resultado, y, por lo tanto, hay una sensación de frustración y miedo. Si uno lo disciplina, lo domina, lo moldea, eso también implica conflicto entre lo que es y lo que debería ser. Y, desde luego, si uno lo reprime, lo sublima, mediante varias formas de identificación — con un determinado grupo, una determinada serie de ideas, una creencia, etc. — todavía habrá conflicto. El deseo parece engendrar conflicto, y creo que la mayoría de nosotros nos damos cuenta de esto (El estado creativo de la mente, p. 66).

Parece que estamos ante un callejón sin salida. Sabemos muy bien que dar rienda suelta al deseo lleva al caos, la autodestrucción y la inmoralidad. En cambio reprimirlo, controlarlo o destruirlo conduce a la insensibilidad, el conflicto, las enfermedades mentales. ¿Qué hacer? Viendo que manejando el deseo se puede controlar a los hombres, la sociedad, que es hipócrita, envía un doble y esquizofrénico mensaje: por un lado pide que controlemos, por otro que disfrutemos a tope:

Y de nuevo la sociedad, que es inmoral, ha dicho: controlen. Por un lado, el lado religioso, dicen: «controlen», pero el mercantilismo dice: «No controlen, disfruten, compren, vendan». ¿ ¿Me sigue? Y la mente humana dice: Todo eso está muy bien. Mi propio instinto es tener placer, de modo que iré tras él. Pero el sábado, el domingo o el lunes o el día que sea, lo dedicaré a Dios (Una manera completamente distinta de vivir, p. 137). 
Ante esta encrucijada, Krishnamurti hace una profunda inmersión en el tema, describiendo primero los hechos y viendo luego causas y consecuencias. Así quedará el camino expedito para hacer claridad en un problema tan sofisticado y a la vez tan decisivo para orientar nuestra conducta. Y va directo al tema: ¿por qué hemos reprimido tanto el deseo, siendo este el motor de la vida? ¿Qué mecanismos tan intrincados se han introducido en este torrente de la vida que es el deseo?

Han sido fundamentalmente tres las causas de la represión del deseo. Primera, que su libre desenvolvimiento acarrea grandes conflictos. Segunda, que lleva a la permisividad y por tanto la moral manda disciplinarlo. Y tercera, que las religiones lo han subyugado en orden a conseguir el encuentro con Dios, la iluminación, la verdad o cualquier otro objetivo en esa línea.

Empecemos por el primero. Tratamos de formar el deseo porque engendra conflicto:

¿Por qué quiere usted lograr la carencia de deseos? ¿Acaso no es porque, por experiencia, ha descubierto que el deseo es penoso, que engendra miedo, conflicto o un éxito que resulta cruel? Por eso ansía hallarse en un estado carente de deseos, el cual puede lograrse, pero es un estado de muerte, ya que es la mera consecuencia del miedo. Usted quiere estar completamente libre de miedo; por lo tanto, convierte la carencia de deseos en el ideal, la norma a la que debe aspirar. Pero el motivo que hay detrás de ese ideal es aún el deseo y, por consiguiente, su esencia sigue siendo el miedo (Obras completas, tomo III, El espejo de la relación, pp. 194-195).

Krishnamurti va ahondando el problema: el deseo engendra conflicto, pero, sin él, vamos camino de la inanidad, el vacío y la negación de la vida:

Queremos destruir el deseo porque el deseo engendra conflicto y sufrimiento. Usted no puede destruir el deseo; si pudiera, se volvería usted nada más que una cáscara vacía. Averigüemos, más bien, qué es lo que da origen al sufrimiento, qué nos impulsa a destruir nuestro deseo.

El deseo está tratando continuamente de satisfacerse, y en su satisfacción hay pesar, sufrimiento y regocijo. De ese modo la mente, para guiarnos y 
prevenirnos, se vuelve el mero depósito de los recuerdos. A fin de que el deseo, en su satisfacción, no pueda generar sufrimiento, la mente se limita y protege con valores e imposiciones basadas en el temor. Así, gradualmente, el deseo se vuelve cada vez más limitado, más estrecho, y de esta limitación se deriva el sufrimiento, el cual nos impulsa a vencer y destruir al deseo o nos obliga a encontrar un nuevo objetivo para ese deseo (Obras completas, tomo II, ¿Qué es la recta acción?, pp. 184-185).

En segundo lugar, y en esta misma línea, el deseo se ha disciplinado en orden a hacer frente a la permisividad y obtener la virtud. Ésta, salvo excepciones, ha sido la tónica general en las diversas culturas:

Viendo entonces todo esto, la permisividad, la reacción al estilo victoriano de la vida, viendo al mundo con todos sus absurdos, sus trivialidades, su banalidad, la respuesta es renunciar a ello, decir, bueno, no lo tocaré. Pero el deseo arde lo mismo, todas las glándulas trabajan. Uno no puede cortar sus glándulas. Por lo tanto, ellos dicen: «Controla, no te sientas atraído hacia una mujer, no mires el cielo porque el cielo es tan maravillosamente hermoso que esa belleza podría convertirse después en la belleza de una mujer, en la belleza de una casa, en la belleza de una silla en la que uno puede sentarse cómodamente. De modo que no mires, controla (Una manera completamente distinta de vivir, pp. 133-134).

Krishnamurti entiende que la permisividad es una reacción a la restricción y al control y que es aquí donde hay que ahondar el problema: ¿qué sentido tiene la disciplina del deseo? Disciplina es el aprender acerca del deseo, no controlarlo. Si aprendemos verdaderamente acerca de algo, ello termina. Pero si decimos que debemos controlar el deseo, eso es algo diferente; porque entonces se trata de taponar ese impulso sin entenderlo. La disciplina, en sentido ortodoxo, no tiene cabida en una mente que desea aprender acerca del deseo. El orden, la disciplina verdadera, surge con la observación del deseo mismo. A menos que comprendamos a fondo la naturaleza del deseo, la mera disciplina nada significa; ésta es una forma de controlar el deseo. Pero controlar nuestros deseos comprime gradualmente el flujo libre de la energía.

El deseo tiene tal fuerza que, si se reprime uno, surge otro de forma distinta: 
Si reprimís el deseo, surge de nuevo en otra forma, ¿̨no es así? Someter a control el deseo es estrecharlo y ser egocéntrico; disciplinarlo es construir un muro de resistencia, que siempre es derribado, a menos, desde luego, que os volváis neuróticos, reducidos a un deseo fijo. Sublimar el deseo es un acto de voluntad; pero la voluntad es esencialmente la concentración de deseo, y cuando una forma de deseo domina a otra, estáis de nuevo en vuestro antiguo tipo de lucha.

El control, la disciplina, la sublimación, la represión: todo ello implica esfuerzo de alguna clase, y tal esfuerzo sigue estando dentro del campo de la dualidad, del deseo «bueno» $\mathrm{y}$ "malo». La pereza puede vencerse por un acto de voluntad, pero la mezquindad de la mente persiste (Comentarios sobre el vivir, $3^{a}$ parte, p. 182).

En este texto, al final, Krishnamurti apunta con claridad la salida del problema: no se trata de echarle voluntad al asunto, reprimiendo el deseo, sino que es la mente la que tiene que aclararse de sus propósitos y de lo que pretende con reprimir el deseo. ¿Qué quiere? ¿Manipularlo en orden a otra cosa, a conseguir un ideal sublime o abyecto que se ha fabricado ella? ¿Por qué no se atiene a la realidad misma del deseo para aprender de él y no a algo ajeno?:

Debemos comprender a fondo la naturaleza interna de la mente misma, y esta comprensión no es cosa de un día; requiere una inmensa percepción alerta de todo nuestro ser. La mente, como he dicho, es un campo de batalla de múltiples deseos, valores, esperanzas, y cualquier esfuerzo que haga para liberarse de todo eso, sólo puede acentuar el conflicto. La lucha existe en tanto continúa el deseo en cualquiera de sus formas; cuando un deseo discrimina contra otro deseo, una serie de valores contra otra, un ideal contra otro ideal, es inevitable que este conflicto continúe. El poder discriminatorio del deseo, de la opción, debe cesar, y esto es posible sólo cuando uno comprende, cuando percibe internamente el ciego esfuerzo del intelecto. La observación profunda de este proceso, observación exenta de anhelos, juzgamientos, prejuicios y, por lo tanto, libre de todo deseo, es el principio de esa percepción alerta que es lo único capaz de liberar a la mente de los temores, hábitos e ilusiones que ella misma engendra y que la destruyen (Obras completas, tomo III, El espejo de la relación, p. 194). 
Es inútil controlar el deseo, está siempre ahí, hagamos con él lo que hagamos. Por eso, lo mejor que podemos hacer es comprenderlo, no destruirlo:

Sigamos examinando el deseo. Conocemos, ¿no es así?, el deseo, el cual se contradice a sí mismo, se tortura, empuja en direcciones diferentes; conocemos la pena, el trastorno, la ansiedad del deseo, y los intentos de disciplinarlo, de controlarlo. Y en la perpetua batalla que sostenemos con él lo retorcemos fuera de toda forma reconocible; pero está ahí, constantemente vigilando, aguardando, apremiando. Haga uno lo que hiciere, sublime el deseo, escape de él, lo rechace, lo acepte o le dé rienda suelta...está siempre ahí (El libro de la vida, 3 de abril).

Tanto si se suprime como si se deja uno llevar por él, el deseo es esencialmente lo mismo, porque sigue estando ahí. Hasta el deseo de suprimirse a sí mismo es también una forma de deseo; de modo que por ahí no hay salida:

Lo que resuelve nuestro problema es comprender la naturaleza de la contradicción, que es el deseo. El deseo jamás puede ser vencido; mas cuando percibimos la verdad de que el deseo siempre crea su propio opuesto y es por lo tanto una contradicción, entonces el deseo llega a su fin (Sólo la verdad trae libertad, p. 117).

Después de esto, uno inevitablemente se pregunta: ¡es posible vivir sin controlar el deseo?:

Mirando, pues, todo esto, señor, uno ve que es terrible lo que los seres humanos se han hecho a sí mismos y a otros. Viéndolo, es inevitable que nos preguntemos: ¿Cómo vivir con el deseo? Usted no puede evitarlo, el deseo está ahí. En el momento en que veo algo, una bella flor, lo admirable que es, su amor, su aroma, la belleza de los pétalos, la claridad de la flor y demás, el goce que implica, surge la pregunta: ¿ Es posible vivir sin ningún control en absoluto? (Una manera completamente distinta de vivir, p. 135).

Antes de responder a esta pregunta que Krishnamurti abordará sobre todo al final, es preciso aclarar la tercera y más profunda causa de la represión del deseo: su descalificación por las religiones. Se acercaron a Krishnamurti un selecto grupo de personas en demanda de orientación en este punto y le preguntaron: 
¿Por qué condenan el deseo las Escrituras? - empezó diciendo el más alto- Prácticamente todos los maestros antiguos parecen haberlo condenado, especialmente el deseo sexual, diciendo que debe ser controlado, subyugado. Es evidente que consideraban el deseo como un obstáculo para la vida superior. El Buda hablaba del deseo como la causa de todo dolor y predicaba su terminación. Shankara, en su compleja filosofía, decía que el deseo y el impulso sexual deben ser suprimidos, y todos los demás maestros religiosos han mantenido más o menos la misma actitud. Algunos de los santos cristianos castigaron sus cuerpos y se torturaban de diversas maneras, mientras que otros sostenían que el cuerpo propio, como el asno o el caballo, debe ser bien tratado pero controlado. No hemos leído mucho, pero toda la literatura religiosa con que nos hemos familiarizado parece insistir en que el deseo debe ser disciplinado, subyugado, sublimado, etc. (Comentarios sobre el vivir, $3^{\text {a }}$ parte, p. 177).

Nunca miramos con calma al deseo. Las religiones, viendo que, dando rienda suelta al deseo, se llega al caos y al conflicto, quisieron cortar por lo sano, entendiendo que la eliminación del deseo llevaba, ipso facto, a una vida superior. Como si hubiese una relación de causa a efecto entre ambas cosas:

Ahora viene la dificultad; dándose cuenta de esto, las personas religiosas han dicho: "Toma votos de celibato, no mires a una mujer; si la miras, trátala como si fuera tu hermana o tu madre, como prefieras, porque tú estás al servicio de Dios y necesitas de toda tu energía para servirle. Al servicio de Dios tendrás grandes tribulaciones; por lo tanto, debes estar preparado, no malgastes tu energía». Pero la cosa hierve, y nosotros tratamos de comprender ese deseo que bulle constantemente anhelando realizarse, completarse (Amor, sexo y castidad, p. 40).

Hay aquí una observación por la que Krishnamurti comienza a hacer luz en el tema. No es el mejor camino para llegar a la virtud, a la verdad, a Dios, etc... el negar o renegar de la belleza de lo natural, incluída nuestra energía vital. Y la negación de esto, que es una espléndida realidad, no puede conducir a nada bueno y sublime:

Una vez en la India, yo caminaba detrás de un grupo de monjes. Eran personas muy serias. Había un monje de edad avanzada que iba rodeado de 
sus discípulos y subían por una colina. Los seguí. Nunca, ni una sola vez, miraban la belleza del cielo, el extraordinario azul del cielo y las montañas, la luz sobre la hierba, los árboles, los pájaros y el agua... Jamás. Ni una sola vez miraban alrededor. Caminaban con las cabezas bajas y repetían algo en sánscrito, totalmente ignorantes de la naturaleza y de quienes pasaban junto a ellos. Habían pasado toda su vida controlando el deseo y concentrándose sobre lo que pensaban que era el camino hacia la realidad. Por lo tanto, el deseo actuaba ahí como un proceso represivo, limitativo (Una manera completamente distinta de vivir, pp. 130-131).

Esa negación de la naturaleza es altamente sospechosa. A renglón seguido hace Krishnamurti la lectura correspondiente del problema que nos ocupa:

En la India eso es algo fantástico; los monjes que han venido a verme — se los llama sanyasis_ — son increíbles. Hace algunos años vino a verme un monje, un hombre bastante joven que había dejado su casa y su hogar a la edad de quince años a fin de encontrar a Dios. Había renunciado a todo vistiéndose con la túnica. A medida que iba creciendo, a los dieciocho años, a los diecinueve, a los veinte, el apetito sexual ardía. Había tomado votos de celibato, como lo hacen los sanyasis y los monjes. Explicó cómo día tras día en sus sueños, en sus paseos, al ir a una casa para mendigar, esta cosa bramaba como un incendio. ¿Sabe lo que hizo para controlarla? Se había operado él mismo. Tan fuerte era su impulso por Dios, ¿entiende, señor? La idea de Dios, no la realidad" (Ibidem, p. 132).

El propio Krishnamurti relata cómo ese mismo monje vino más tarde, después de oírle. Vino llorando amargamente, lamentando lo que había hecho consigo mismo. Aunque la castración física es un caso extremo, hay muchas formas de castración y todas ellas se mueven en esa misma dirección. Cita también al cristiano Orígenes que hizo otro tanto; y, por la misma razón, se arrepintió igualmente aunque ya no cabía remedio.

Krishnamurti anota muy bien lo que al final le confesó el monje hindú: «He cometido un pecado, he cometido un acto perverso». ¿De qué pecado se trataba? Pecado de lesa naturaleza. Creer que para llegar a Dios hay que quebrantar la naturaleza es una perversión; y sin duda también un insulto al creador que hizo todas esas cosas y las consideró buenas y bellas. 
Krishnamurti señala el resultado de ese desastroso proceso: el envaramiento y la insensibilidad de la mente reprimida:

Ahora bien, veamos primero qué le ocurre a una mente que siempre se está controlando, que reprime, sublima el deseo. Una mente así, estando ocupada consigo misma, se vuelve insensible. Aunque pueda hablar de sensibilidad, bondad, aunque pueda decir que debemos ser fraternales, que debemos producir un mundo maravilloso y todas esas insensateces de que hablan las personas que reprimen el deseo, una mente semejante es insensible, porque no comprende aquello que ha reprimido. Es esencialmente lo mismo que uno reprima el deseo o que sucumba a él, porque el deseo sigue estando ahí (Amor, sexo y castidad, p. 46).

Todo es poco para avisar que estamos aquí en un momento álgido:

Si reprimen el deseo, entonces se están destruyendo a sí mismos, se paralizan, se vuelven insensibles, torpes, estúpidos, como han hecho todas las personas que se titulan religiosas; a causa de que han reprimido el deseo se han negado a la belleza, a la sensibilidad. Mientras que si uno comienza a comprender toda la sutileza del deseo, la naturaleza del deseo, jamás reprimirá el deseo, jamás reprimirá nada (Ibídem, pp. 50-51).

\section{Significado e intencionalidad del deseo}

Después de estos últimos textos, Krishnamurti ha despejado el camino. Y ha despertado la sensibilidad para mirar sin prejuicios esa realidad tan importante que es el deseo. Y así hace una inmersión a fondo. Tratando de adentrarse en su esencia, intenta que se despliegue ante nosotros la intencionalidad misma, el significado del deseo.

De esta manera, conectando con el apartado anterior, para ir siguiendo la unidad del curso de la reflexión, Krishnamurti afirma a los cuatro vientos: "No juzguéis, no condenéis el deseo, nada de malo hay en él". Era necesario insistir en este punto después del tremendo problema de la represión. Es verdad que el deseo conlleva placer y dolor y eso le hace especialmente problemático. Pero, por eso mismo, es necesario comprenderlo bien y no prejuzgarlo de antemano: 
Tenemos que comprender el deseo, y es muy difícil comprender algo que es tan exigente, tan apremiante, porque en la satisfacción misma del deseo se engendra la pasión con su placer y su dolor. Y si uno ha de comprender el deseo, es obvio que no debe haber opción alguna. No podemos juzgar el deseo como bueno o malo, noble o innoble, ni decir: «Mantendré este deseo y rechazaré aquel otro». Todo eso hay que dejarlo de lado si hemos de descubrir la verdad acerca del deseo: su belleza, su fealdad o lo que fuere (Amor, sexo y castidad, pp. 59-60).

Es pues muy difícil comprender el deseo sin juzgarlo. Pero no hay por qué librarse de él. Hay que dejarle en paz; dejarle que se desate o que se consuma, sólo dejarle en paz. Esa es la verdadera postura de una mente que no está en conflicto con él. Si se comprende esto, no existe el problema de la represión del deseo. Porque cuando uno lo reprime, genera inevitablemente conflicto. En esto abunda Krishnamurti: la mente no tiene por qué reprimir nada, ni el deseo, ni el temor, ni la enfermedad. Hablando de ésta, en parangón con el deseo, dirá que no hay que sofocarla inmediatamente. La enfermedad tiene su intencionalidad y mensaje que hay que saber descifrar:

Uno no pude reprimir una enfermedad; tiene que ponerla de manifiesto, examinarla, hacer toda clase de cosas. Pero si la reprime, si la sofoca, ella ganará en potencia, se fortalecerá y más tarde va a atacarlo. De igual modo, cuando usted comprende toda la naturaleza del deseo y qué es lo que le da continuidad, jamás, bajo ninguna circunstancia, reprimirá el deseo. Pero eso no quiere decir que haya de abandonarse al deseo. Porque tan pronto se abandona al deseo, ello trae su propio placer y su propio dolor, y usted está de vuelta en el círculo vicioso (Ibidem, p. 52).

¿Y esto por qué? ¿Por qué no hay que reprimir el deseo? Porque nada de malo hay en él:

Cuando veo un árbol meciéndose en el viento, es algo hermoso de ver, ¿y qué tiene eso de malo? ¿Qué tiene de malo mirar el bello movimiento de un pájaro en vuelo? ¿Qué tiene de malo mirar un auto nuevo, hecho a la perfección y muy pulido? ¿Y qué tiene de malo ver a una persona agradable, con un rostro simétrico, una cara que refleja sensatez, inteligencia, calidad? (Reflexiones sobre el ser, p. 138). 
Es posible ver, observar esas cosas bellas y feas de la vida y no emitir juicios sobre ellas ni decir si se debe poseerlas o no. Observando así las cosas, se descubre que el deseo no tiene nada de misterioso. Lo que pasa es que siempre hemos hecho algo con él, tratando de poseer cosas, lograr poder, placer o lo que sea. Pero cuando la mente no trata de modelarlo ni interferir en él, entonces se manifiesta como una fuerza en la que nada hay de malo o reprochable. El problema empieza cuando el deseo crea conflicto, cuando el anhelo de posesión pervierte la inocencia del deseo. Entonces éste se hace apremiante y compulsivo. Pero si comprendemos esto y cerramos el acceso a la posesividad, entonces el deseo tiene un significado diferente.

Aquí Krishnamurti da un paso más en esta reflexión. Alejada del deseo el ansia de posesividad, éste se muestra como motor de nuestra sensibilidad. Un hombre sin deseos es como una cáscara vacía; carece de capacidad de gozo, sensibilidad y vida. El deseo es el movimiento mismo de la vida:

Si destruimos el deseo, hay muerte. Y si nos limitamos a cambiar el objetivo del deseo, si encontramos nuevos ideales para el deseo, entonces sólo estamos escapando del conflicto, y así no puede haber riqueza ni plenitud. Si no hay una limitada, egoísta persecución de objetivos o ideales, entonces el deseo es, en sí mismo, el movimiento continuo de la vida (Obras completas, tomo II, ¿Qué es la recta acción?, p. 185).

El modo como tratamos de dominar nuestros deseos nos hace seres mediocres y vacíos:

Después de todo, las vidas que hacemos ahora, basadas en las necesidades, los deseos y los medios de dominar el deseo, nos hacen más superficiales y vacíos que nunca. Podemos ser muy sagaces, muy instruidos, capaces de repetir lo que hemos acumulado; pero eso lo hacen las máquinas electrónicas, y ya en algunos campos las máquinas son más capaces que el hombre, más exactas y veloces en sus cálculos (El estado creativo de la mente, p. 260).

Por consiguiente, el deseo implica ser sensibles:

El problema, pues, es comprender el deseo y no ser un esclavo de él, lo cual implica ser totalmente sensibles, con nuestro cuerpo, nuestra mente y 
nuestro corazón, sensibles a la belleza y a la fealdad, al cielo, a las flores, a los pájaros en vuelo, al crepúsculo sobre las aguas, a los rostros que nos rodean, a la hipocresía, a la falsedad de nuestras propias ilusiones. Lo que importa es ser sensibles a todo eso y no cultivar tan sólo la sensibilidad respecto a la verdad y la belleza mientras negamos todo lo demás. La negación misma de todo lo demás es lo que da origen a la insensibilidad (Amor, sexo y castidad, p. 54).

De modo que Krishnamurti está ahondando la intencionalidad del deseo. Debajo del deseo están los sentidos, la sensibilidad, el amor a la vida. Y eso es la gloria de nuestra existencia:

Si lo consideran, verán que reprimir los sentidos, tornarlos insensibles a lo que es tempestuoso, contradictorio, conflictivo, doloroso, como insisten en aconsejar todos los swamis, yoguis y las religiones, es negar toda la profundidad, belleza y gloria de la existencia. Para comprender la verdad, ustedes deben tener sensibilidad completa. ¿Entienden, señores? La realidad exige la total entrega de nuestro ser: deben llegar a ella con su cuerpo, su mente y su corazón, como seres humanos totales, no con una mente paralizada e insensibilizada por la disciplina. Entonces descubrirán que no necesitan temer a los sentidos, porque sabrán cómo habérselas con ellos y ellos no los descarriarán. Comprenderán los sentidos, los amarán, verán todo su significado, y entonces ya no se torturarán más con la represión, el control. ¿No ven eso, señores? (Ibidem, p. 54).

La conclusión de esta precisa exposición es un canto a la sensibilidad que nos viene sólo a través del deseo. Esa sensibilidad nos hace a la vez vulnerables, pero injertados en la vida misma. Dejar de tener deseos y por tanto de ser sensibles es volverse paralítico, es morir. Vivir sin deseos es estar en la tumba y en ésta no podemos tratar de ser sensuales.

Krishnamurti sigue tejiendo los hilos de esta reflexión. Y ahora se pregunta ¿qué ocurre si no se juzga, si no se reprime el deseo? Acabamos de ver que el deseo es la fuente de la sensibilidad. Pero cuando la mente sigue sin interferir la corriente de esa sensibilidad, entonces el deseo, aunque sea feo, violento y dominante, deja de ser causa de perturbación y lo captamos como una totalidad: 
Y si uno hace lo mismo con el deseo, si vive uno con él — sin negarlo ni decir "¿qué haré con este deseo que es tan feo, tan dominante, tan violento?», sin darle un nombre, un símbolo, sin encubrirlo con una palabraentonces ¿no deja ya de ser causa de perturbación? ¿Es entonces el deseo algo que haya que eliminar, destruir? Queremos destruirlo porque un deseo se opone a otro, creando conflicto, desdicha y contradicción; y puede uno ver cómo trata de escapar de este perpetuo conflicto. ¿Podemos, pues, darnos cuenta de la totalidad del deseo? Lo que quiero decir con «totalidad» no es puramente un deseo o muchos, sino la cualidad total del deseo mismo. Y puede uno darse cuenta de la totalidad del deseo sólo cuando no hay opinión sobre él, ni palabra, ni juicio, ni elección (El estado creativo de la mente, p. 259).

Pero ahora llega el punto álgido. Cuando la mente capta la totalidad del deseo, éste se convierte en pasión:

Dándose cuenta de todo deseo según surge, no identificándose con él ni condenándolo, en ese estado de alerta, ¿hay entonces deseo, o es una llama, una pasión que es necesaria? La palabra "pasión» se reserva generalmente para una cosa: el sexo. Mas, para mí, la pasión no es el sexo. Debéis tener pasión, intensidad, para vivir realmente con cualquier cosa; para vivir plenamente, para mirar una montaña, un árbol, para mirar realmente un ser humano, debéis tener una apasionada intensidad. Pero esa pasión, esa llama, no existe cuando estáis cercados por diversos apremios, exigencias, contradicciones, temores. ¿Cómo puede subsistir una llama cuando está sofocada por tanto humo? Nuestra vida no es sino humo. Estamos buscando la llama, pero la rechazamos al reprimir, al dominar, al moldear la cosa que llamamos deseo (Ibidem, p. 259).

El deseo, pues, observado en su intensividad y bajo la mirada atenta y no escrutadora de la mente, ha llegado a ser la llama, la auténtica pasión para poder vivir. Krishnamurti se detiene aquí un momento para describir la cualidad de esa llama. Es una fabulosa energía que tiene sentido en sí misma sin que nadie desde fuera quiera usufructuarse de ella:

Como el vapor, el deseo es energía ¿`verdad? Y así, como el vapor puede ser dirigido para mover toda clase de maquinaria, beneficiosa o destructiva, 
así también el deseo puede ser disipado, o puede ser utilizado para la comprensión, sin que haya ningún usufructuario de esa asombrosa energía. Si hay un usufructuario, tanto si es uno como los muchos, el individuo o lo colectivo, que es la tradición, entonces empieza el trastorno; entonces existe el círculo cerrado del dolor y el placer (Comentarios sobre el vivir, tercera parte, p. 182).

Es ahora cuando Krishnamurti aclara desde esta perspectiva la génesis de la problemática del deseo: éste, en sí, es energía que tiene su propio sentido: quien frustra éste es el sujeto individual o colectivo que la utilizan para fines espúreos; éstos pervierten la fuerza e inocencia del deseo:

Sólo existe la energía; no existe la cuestión de quién la utilizará. No es esa energía, sino el usuario, quien sustenta la confusión y la contradicción del dolor y el placer. El utilizador, bajo la forma del uno y de los muchos, dice: «Esto está bien y eso está mal. Esto es bueno y eso es malo», perpetuando con ello el conflicto de la dualidad. Él es el verdadero autor del daño, del dolor. ¿Puede dejar de existir el utilizador de esa energía llamada deseo? ¿Puede el observador no ser un operador, una entidad separada que encarna esta o aquella tradición, y ser esa energía misma? (Ibídem, pp. 182-183).

Este es el único problema aunque sea difícil comprenderlo. Y ello va acorde con una de las constantes del pensamiento y la enseñanza de Krishnamurti. El problema es comprender el deseo, no controlarlo, disciplinarlo o sublimarlo. Cuando se ve esto, cuando el sujeto no interfiere el deseo, entonces éste tiene una significación por completo diferente. Entonces el deseo es el movimiento de la vida, la pureza de la creación, el móvil hacia la verdad. Pero quede claro que lo importante es el cese del sujeto, del utilizador del deseo. Cuando esto sucede sólo hay energía que destruirá lo viejo y lo negativo.

Y este deseo, todo energía, que funciona sin el control del sujeto es lo que Krishnamurti denomina deseo completo. Ese deseo no se fragmenta; es un bloque de energía. Y con él se pueden afrontar los retos de la realidad y de la vida. El problema es que no tenemos deseos completos que acaparen nuestro ser entero. Queremos cosas sueltas; saltamos futilmente de una cosa a otra. No existe en nosotros un deseo vertebrador de nuestro ser. De ahí nuestra indigencia: 
Si su deseo de hacer algo es completo, si todo su ser está en ello sin buscar un resultado, sin el anhelo de satisfacción —o sea, sin temor- entonces no hay obstáculos. Un obstáculo, una contradicción existen sólo cuando su deseo es incompleto, cuando está fragmentado: uno desea hacer algo $y$, al propio tiempo, teme hacerlo, o quiere hacer a medias alguna otra cosa. Además, ¿puede uno realizar alguna vez plenamente sus deseos? (El propósito de la educación, pp. 148-149).

Este deseo completo es lo que hace íntegro al hombre. Lo que le orienta en una dirección. Lo que da unidad y fuerza a su vida. Pero aquí le asalta al hombre un enemigo: la sociedad. A ésta no le interesan hombres así, de deseos plenos, porque son un obstáculo para sus fines poco confesables:

La sociedad, que es la relación colectiva entre los hombres, no quiere que uno tenga un deseo completo, porque si lo tuviera sería un estorbo, un peligro para la sociedad. Se nos permite tener deseos respetables como la ambición, la envidia - eso está perfectamente bien. Estando constituida por seres humanos envidiosos, ambiciosos, que creen e imitan, la sociedad acepta la envidia, la ambición, la creencia, la imitación, aun cuando todas éstas sean intimaciones del temor. En tanto sus deseos encajan en el patrón establecido, es usted un ciudadano respetable. Pero tan pronto tiene un deseo completo que no pertenece al patrón, se vuelve usted un peligro; por ende, la sociedad está siempre vigilando para impedirle que tenga un deseo completo, un deseo que sería la expresión de su ser total y que, en consecuencia, daría origen a una acción revolucionaria (Ibidem, p. 149).

\section{La comprensión del deseo}

A estas alturas del camino, Krishnamurti ha ido desvelando paulatina y pedagógicamente la intencionalidad del deseo. Estamos ya a las puertas mismas de su extraña esencia. En cierto modo acaba de indicarlo en alguno de los textos anteriores. Es la comprensión la que nos guía al verdadero descubrimiento del deseo. Por ella penetramos en un terreno verdaderamente nuevo, bien diferente al que conducen la domesticación y represión de aquél. 
En apartados anteriores, Krishnamurti ha ido insistiendo en que lo importante es comprender el proceso del deseo y no tanto el de poner límite al anhelo de posesión. Cuando se comprende el deseo mismo, se ve lo que implica y entonces la acción no nacerá del esfuerzo ciego, sino que surgirá espontáneamente de esa misma comprensión:

¿Qué entendemos por comprender el deseo? El deseo no es estático; no podemos imponerle determinadas normas y regulaciones si es que queremos comprenderlo. Debemos seguirlo, observarlo, debemos seguir cada movimiento de sus intrincados caprichos y de sus fantasías, tanto conscientes como inconscientes, ¿no es así? No podemos decir: «Ése es un deseo correcto. Ese otro es un deseo incorrecto. Esto está muy bien. Esto es lo que deseo hacer», etc. Cuando decimos eso, ponemos fin a la comprensión y subsecuente seguimiento de ese deseo (Obras completas, tomo VI, El origen del conflicto, p. 325).

Hacer este seguimiento no es fácil porque desde la infancia hemos sido educados para reprimir, controlar y dominar el deseo. Entonces, si seguimos la investigación hasta el final, veremos que, en el deseo, opera un centro que está siempre en proceso de reconocimiento. Todas nuestras experiencias se acumulan en la memoria bajo ese centro de reconocimiento que es el yo. No hay experiencia si no hay reconocimiento. Si yo no reconozco algo, no tengo experiencia de ello. $\mathrm{Si}$ el yo no reconoce algo como suyo, lo abandona. Entonces se trata de comprender el deseo sin ese centro de reconocimiento. Para comprender algo, lo que sea, debe cesar ese centro de reconocimiento y experiencia. Si no, no nos encontraremos con las cosas reales, sino con nuestra proyección sobre ellas. En vez de hallar las cosas mismas, nos toparemos con nuestra sombra sobre ellas, con nuestra experiencia proyectada. Se trata pues de ir a las cosas mismas sin experiencia ni reconocimiento. Pero es que lo que da fuerza al reconocimiento es el deseo. Entonces es preciso comprender el deseo, seguirle no como algo ajeno a uno mismo y eso será la auténtica revolución interna:

Para comprender, pues, este problema de la existencia, con toda su confusión, su desdicha, sus tribulaciones, negaciones y aflicciones extraordinarias, no hay duda de que debemos comprender el deseo, seguir hasta el fin su movimiento. Y sólo podemos seguirlo así cuando la mente se percibe a sí misma, cuando uno no considera al deseo como algo ajeno a uno mismo. 
Miren, señores. Digamos que tengo un deseo. ¿Qué hago? Mi reacción instintiva es condenarlo, decir: «iQué tonto, qué estúpido es!» o decir: “iQué bueno es, qué noble!». ¿Qué ocurre, entonces? No he seguido realmente el movimiento del deseo, no lo he investigado, no lo he comprendido; no le he puesto fin. Tengan la bondad de considerar esto a fondo y verán su extraordinaria importancia. Entonces, les aseguro, tendrán una revolución, la más grandiosa de las revoluciones (Ibidem, pp. 326-327).

Se trata por tanto de seguir el movimiento mismo del deseo hasta el final, sin interferencias nuestras que lo desvíen u oscurezcan. Por tanto, en ese momento, poco importa si debemos limitarle o librarnos de él. Es preciso comprenderle y luego vendrá lo demás:

Nuestro problema, pues, es el de comprender el deseo, no hasta dónde debiera ir, o adónde debiera terminar, sino el de comprender todo el proceso del deseo, las ansias, los anhelos, los apetitos vehementes. Muchos de nosotros creemos que el poseer muy poco indica liberación del deseo, ¡y qué culto rendimos a los que no tienen más que unas pocas cosas! Un taparrabos o una túnica simbolizan nuestro deseo de estar libres de deseo; pero ésa sigue siendo una reacción muy superficial. ¿Por qué empezar en el nivel superficial abandonando las posesiones materiales cuando vuestra mente está paralizada por los innumerables deseos, creencias y luchas? Es aquí, ciertamente, donde la revolución debe producirse, no en el número de vuestras posesiones, o en la ropa que usáis, o en cuántas veces coméis. Pero esas cosas nos impresionan porque nuestra mente es muy superficial (La libertad primera y última, p. 105).

Se trata pues de comprender el proceso del deseo y así surgirá la limitación natural de las cosas:

Lo que tratamos de hacer aquí es comprender el proceso del deseo, no poner un límite al anhelo de posesión. Al comprender el anhelo, surge una limitación natural de las cosas, no una limitación predeterminada producida por el ejercicio de la voluntad. Es el anhelo de posesión el que da a las cosas sus valores desproporcionados. Esos valores se basan en los requerimientos psicológicos. Si uno es psicológicamente pobre, busca satisfacción en las cosas; por lo tanto, la propiedad, el nombre, la familia, se vuelven 
perentorios e importantes y dan por resultado el caos social. En tanto uno no haya resuelto este conflicto de la codicia, la mera limitación de las cosas no podrá producir ni orden social ni ese sosiego que implica la libertad respecto del anhelo (Obras completas, tomo III, El espejo de la relación, p. 213).

Para estar libre del anhelo, uno debe pacientemente, sin prejuicios, comprender su complejo proceso. Krishnamurti sigue de cerca los recovecos que recorre el deseo: cuando uno no triunfa en una determinada dirección, sigue otra y así en una búsqueda sin término, en un anhelo inextingible. ¿Qué hay detrás? El deseo es una constante ambición de cosas de todo género que no acaba nunca. ¿Se ve claro esto?:

Ello quiere en realidad decir: ¿puede uno vivir en este mundo sin ambición? ¿Podéis ir a la oficina y trabajar sin ambición? Y, si lo hicierais, ¿no os barrería vuestro competidor? ¿Y no existe el miedo de que, si no hubiera ambición, sería uno simplemente eliminado? Si puedo sugerirlo, planteaos el siguiente interrogante: cuando preguntáis qué hacer con el deseo ¡tenéis que pasar primero por todas las formas de realización con sus frustraciones, desdichas, temores, delitos y ansiedad? O quizá nunca os hayáis planteado siquiera esa cuestión, sino que sólo estáis reprimiendo todo el tiempo. Tal vez, si no habéis hallado felicidad, posición, prestigio, en cierta dirección, os volváis hacia otra; éstas son sus expresiones exteriores e interiores. Cuando uno es un nadie en este mundo en desintegración, se vuelve hacia la realización interior (El estado creativo de la mente, p. 69).

Al llegar aquí, al encontrarnos con que el deseo bulle en todas las direcciones y no se sacia, nos encontramos con nuestro propio yo que se siente nada y quiere satisfacerse como sea, en todas las direcciones. Entonces nos encontramos con nosotros mismos, con lo que somos. Y nos topamos con nuestra propia contradicción: anhelamos poseer cosas externas o internas, y no nos satisfacen:

Así pues, si queremos comprender la contradicción en que vive la mayoría de nosotros, tiene que haber conocimiento propio, que es la comprensión del deseo; y sin comprender todo el proceso del deseo, no resolveremos nuestro problema mediante el mero seguimiento de un deseo en particular. Lo que resuelve nuestro problema es comprender la naturaleza de la contradicción, la cual es deseo. El deseo jamás puede ser vencido, pero cuando vemos 
la verdad de que el deseo genera siempre su propio opuesto y, por ende, contradicción, entonces el deseo llega a su fin; sólo así es posible contentarse con la necesidad (Obras completas, tomo VI, El origen del conflicto, p. 297).

De modo que siguiendo la llamada de cada uno de los deseos particulares no se llega a ninguna parte. Un deseo satisfecho reclama otro y así sin fin. Es aquí donde Krishnamurti plantea la acción del ser y la acción del devenir para saber el terreno que pisamos. Los deseos no se realizan jamás porque no tienen fin, porque se sitúan en el plano del «llegar a ser» y éste no se realiza nunca, es un continuo aspirar sin llegar. Este es el plano del devenir que es el de la realización que no llega a término:

Esta es una cuestión muy importante que hay que investigar, porque a medida que pasen los años ustedes encontrarán que sus deseos jamás se realizan realmente. En la realización está siempre la sombra de la frustración, y entonces no llevan ustedes en el corazón un canto sino un grito. El deseo de llegar a ser - llegar a ser un gran hombre, un gran santo, un gran esto o aquello- no tiene fin y, por tanto, no re realiza nunca; siempre exige «más», y un deseo semejante engendra permanentemente angustia, desdicha, guerras. Pero cuando uno está libre de todo deseo de devenir, hay un estado del ser cuya acción es por completo diferente. Es. Y lo que es, no pertenece al tiempo. No piensa en términos de realización. Su existencia misma es su realización (El propósito de la educación, pp. 149-150).

Por eso la sociedad rechaza a los que han visto que no siguen su patrón que es el devenir. La sociedad pide que no nos contentemos con lo que somos, sino que estemos siempre "superándonos», es decir, creando nuevos intereses que tiran de nosotros. Y esto nos lleva a la frustración:

La acción del ser es por completo diferente de la acción del devenir. La acción del ser es tan revolucionaria que la sociedad la rechaza y se interesa exclusivamente en la acción del devenir, la cual es respetable porque encaja dentro del patrón. Pero cualquier deseo que se expresa en la acción del devenir — que es una forma de ambición — carece de una realización completa. Tarde o temprano, ese deseo se ve contrariado, impedido, frustrado, y contra esa frustración nos rebelamos mediante procedimientos dañinos (Ibidem, p. 149). 
Ahora, en este contexto, sí que se entiende y tiene sentido hablar de cese o liberación del deseo, y no antes. Y, más bien, como quedó perfilado más atrás, de cese de nuestros particulares objetos de deseo y no del deseo mismo. Sólo cuando se comprende el significado interno del deseo, esa comprensión está empezando a disolver espontáneamente los deseos y todo aquello que en nosotros busca satisfacción. Y justamente la liberación espontánea de estos deseos psicológicos concretos dará lugar, como se verá enseguida, al amor.

Krishnamurti insiste ahora en la liberación de esas urgencias inmediatas que plantean nuestros deseos:

Qué fácil es engañarse uno mismo acerca de casi todo, especialmente con respecto a las más profundas y sutiles urgencias y deseos. Es arduo estar enteramente libre de todas estas urgencias e impulsos. Sin embargo, es esencial liberarse de ellos o de otro modo el cerebro engendra todas las formas de ilusión. El impulso por repetir una experiencia, no importa lo placentera, bella o provechosa que haya sido, es el terreno donde crece y se desarrolla el dolor. La pasión del dolor es tan limitadora como la pasión del poder. El cerebro debe cesar de moverse por sí mismo, y ha de estar completamente pasivo (Diario I, p. 27).

Pero, para proceder a la catarsis de los deseos, es preciso ver claro la causa de ésta: ser indiferente a ellos:

Qué fácil es engañarse uno mismo, proyectar estados que se desean y experimentarlos realmente, en especial cuando implican placer. No hay ilusión ni engaño cuando no existe el deseo, consciente o inconsciente, de experiencias de ninguna clase, cuando uno es por completo indiferente al ir y venir de toda experiencia, cuando uno no pide absolutamente nada (Diario I, p. 37).

En uno de los textos anteriores, y ahora es el momento de verlo y tratarlo debidamente, aparecía la idea de que la liberación espontánea de los deseos daba lugar al amor. También quedó manifiesto en el apartado anterior que el deseo liberado se convierte en una inmensa energía y pasión. Krishnamurti detalla esto dada su trascendencia. La vida, consumida en la satisfacción de nuestros innumerables y contradictorios deseos, aboca al hastío y la nada: 
Volvemos, pues, siempre a lo mismo, que es la vida, tal como la vivimos, es muy superficial, estrecha, limitada y todo porque en lo hondo estamos vacíos, solitarios, y siempre tratando de ocultarlo, de llenar ese vacío; por consiguiente la necesidad, el deseo, llegan a ser una cosa terrible. Nada puede llenar ese profundo vacío interior, ni los dioses, ni los salvadores, ni el conocimiento, ni las relaciones, los hijos, el marido ni la esposa; nada. Pero si la mente, el cerebro, la totalidad de vuestro ser puede ver eso, vivir con ello, entonces veréis que, psicológicamente, íntimamente, no hay necesidad de nada. Esa es la verdadera libertad (El estado creativo de la mente, p. 260).

Pero ahora Krishnamurti pone delante quizá lo más decisivo del problema del deseo: que cuando se ha estado atento a su dinámica y se le ha liberado de su dispersión, entonces el deseo, limpio del uso meramente placentero, se convierte en pasión y amor. $\mathrm{O}$ dicho de otra manera, entonces el amor, el deseo y la pasión son la misma cosa:

Mas eso requiere muy honda penetración, profunda indagación, vigilancia incesante; y, partiendo de eso, tal vez conoceremos qué es el amor. ¿Cómo puede haber amor cuando hay apegos, celos, envidia, ambición, y toda la ficción que va con esas palabras? Entonces, si hemos pasado por ese vacío - que es un hecho, no un mito, no una idea — hallaremos que el amor y el deseo y la pasión son la misma cosa. Si destruís uno, destruís los otros; si corrompéis uno, corrompéis la belleza. Para penetrar en todo esto, hace falta no una mente desligada, no una mente consagrada, o religiosa, sino una mente que esté indagando, que nunca esté satisfecha, que siempre esté mirando, vigilando, observándose, conociéndose. Sin amor, nunca descubriréis qué es la verdad (Ibidem, pp. 260-261).

Es decir, cuando hay un cese espontáneo de los deseos, entonces hay una renovación de nuestro ser. Y el deseo liberado se convierte en emoción profunda cuyas manifestaciones son la energía, la verdadera pasión, el amor, la belleza y la bondad. Pero en este texto Krishnamurti insiste en algo que es vertebral en su enseñanza: que no se llega aquí por esfuerzos de voluntad ni por adiestramiento o represión del deseo. Es por la atenta observación y, por consiguiente, comprensión. La intensidad de la observación tiene su propia acción que no es la acción contradictoria del deseo: 
Y cuando el amor es intenso, el deseo pronto desaparece. Pero la mayoría de nosotros nunca hemos tenido esta intensidad respecto a nada, excepto en lo que concierne a nuestro propio beneficio, consciente o inconsciente; nunca tenemos pasión por nada sin esperar obtener otra cosa de ello. Pero sólo la mente que posee esta energía intensa es capaz de seguir el rápido movimiento de la verdad.

La verdad no es estática, es más rápida que el pensamiento, y la mente no puede concebirla de ningún modo. Para comprender la verdad, debe haber esta inmensa energía, la cual no puede ser conservada o cultivada. Esta energía no viene por medio de la abnegación, mediante la supresión. Al contrario, exige completo abandono; y usted no puede abandonarse a sí mismo o abandonar todo lo que tiene, si meramente quiere un resultado (Reflexiones sobre el ser, p. 139).

Krishnamurti sondea una y otra vez esa realidad a la que se llega cuando es comprendido el deseo: realidad de energía, belleza y amor. Hay un texto suyo que resume todo el trayecto y con el se cierra este apartado:

Por lo tanto, un hombre que quiera comprender el deseo tiene que entender, tiene que escuchar cada sugerencia de la mente y del corazón, tiene que prestar atención a cada disposición del ánimo, a cada cambio del pensar y del sentir, tiene que vigilar todo eso; debe volverse sensible, alerta a ello. No podemos estar atentos al deseo si lo condenamos o lo comparamos. Tenemos que cuidar del deseo, porque ello nos dará una comprensión enorme. Y gracias a esa comprensión hay sensibilidad. Entonces somos sensibles no sólo físicamente a la belleza, sino también a todos los murmullos y susurros de nuestra mente, a las esperanzas secretas, a los temores ocultos.

De este escuchar y observar surge la pasión, esta pasión que es de la misma naturaleza que el amor. Sólo este estado puede cooperar. Por eso, gracias a esta profundidad de comprensión, a este observar, la mente llega a ser eficiente, clara, plena de vitalidad, de vigor; sólo una mente así puede viajar muy lejos (Amor, sexo y castidad, p. 49).

En definitiva, el deseo es el motor por excelencia que nos conduce a la vida, a la exploración de todas nuestras posibilidades, a la búsqueda de compleción de nuestro ser en las más diversas y, a veces, divergentes direcciones. Sin él, la exis- 
tencia resultaría un fenómeno frío e inmovilizado. Pero es preciso una continua vigilancia sobre él, no contención ni represión. La mirada atenta, afectuosa y comprensiva sobre él bastará para que suministre la energía necesaria en orden a una integración interna y no a la polarización destructiva de alguna de sus múltiples salidas. Esa integración suministra a nuestro ser la plenitud vital para conducir a éste a su destino.

\section{Bibliografía}

KrishnamurTi (1994-2000) Obras completas, Buenos Aires: Kier.

Tomo I. El arte de escuchar

Tomo II. Qué es la recta acción

Tomo III. El espejo de la relación

Tomo IV. El observador es lo observado

Tomo V. Percepción sin opciones

Tomo VI. El origen del conflicto

KrishnamurTi (1992). El estado creativo de la mente, Buenos Aires: Kier.

- (1992). Sólo la verdad trae la libertad, Buenos Aires: Kier.

- (1994). Una manera completamente distinta de vivir, Buenos Aires: Kier.

- (1992-94). Comentarios sobre el vivir, tres volúmenes, Buenos Aires: Kier.

- (1992). Diario I, México, Sudamericana.

- (2002). Amor, sexo y castidad, Barcelona: Kairós.

- (1996). La libertad primera y última, Barcelona: Kairós.

- (1999). Limpia tu mente, Barcelona: Martínez Roca.

- (1996). El libro de la vida, Madrid: Edaf.

- (1992). El propósito de la educación, Barcelona: Edhasa.

Recibido: 19/10/2011

Aceptado: 25/11/2011 